\title{
The Effect of Clay Content and Land Use on Dispersion Ratio at Different Locations in Sulaimani Governorate-Kurdistan Region-Iraq
}

\author{
Saman M. K. Rasheed \\ Department of Soil and Water Sciences, Faculty of Agricultural Sciences, Sulaimani University, Sulaimani, Iraq \\ Email: saman.karim@univsul.edu.iq
}

Received 26 October 2015; accepted 17 January 2016; published 20 January 2016

Copyright (C) 2016 by author and Scientific Research Publishing Inc.

This work is licensed under the Creative Commons Attribution International License (CC BY). http://creativecommons.org/licenses/by/4.0/

\section{(c) (i) Open Access}

\begin{abstract}
Land use changes from natural ecosystems into managed ecosystems resulted in negative impact on soil structure and quality. The purpose of this study was to determine the influences of different land-use types on physical and chemical properties of soils in Sulaimani governorate. Land use systems including natural forest, pastureland and agriculture were identified. Ten of soil samples were collected from the $0-30 \mathrm{~cm}$ depth, and some soil physical and chemical properties of soil were determined. The land use alters from forest to agriculture resulting in significant decrease in organic matter, calcium carbonate and soil surface area and with this change, dispersion ratio affected on the physical property. The value of $D R$ was highest in the Zrguezi Gawra cultivated with Cucumber and the lowest value in Dukan is $13 \%$, and correlation coefficient between dispersion $D R$ with sand, silt and bulk density is positive, value is $(0.4979,0.0126$ and 0.7536$)$ respectively, and with clay and specific surface area (SSA) the correlation coefficient value is $(-0.7281$ and -0.4466).
\end{abstract}

\section{Keywords}

Particle Size Distribution, Dispersion Ratio, Bulk Density, Organic Matter

\section{Introduction}

The lack of success of dams and embankments as a result of the use of dispersive soil has been recognized by 
engineers and geologists in South Africa and internationally for many years. A serious problem, however, yet lies in the early identification of dispersive soils [1]. In spite of all the knowledge obtained over the years, there is still no fast, simple and dependable mean of conclusively recognizing dispersive soils. Many methods have been suggested including the pinhole, double hydrometer, crumb and chemical tests, individually or in group. These, but, have not always been totally credible and it looks like that the cause sets in the factual testing procedures. The standard testing procedures for the Soil Conservation Service (SCS) double hydrometer test, the pinhole test, crumb test and chemical analyses have lately been studied and problems/abnormalities identified. Although no discussion concerning these anomalies has been discovered in the literature, the recent testing proposes that many of these deficiencies may have been looked out during past routine investigations. This paper summarizes a proportional study including the testing of three specimen utilizing one standard laboratory test, namely the SCS double hydrometer test and discusses some potential means of conquering the problems identified. The other tests have been discussed separately [2]-[5].

SCS double hydrometer or dispersion soil test has been identified as one of the most suitable tests for classifying dispersive soils. The test assesses the dispersibility of a soil by measuring the natural propensity of the clay fraction to go into annotate in water. The procedure involves the estimation of the percentage of particles in the soil that are finer than $0.005 \mathrm{~mm}$ utilizing the standard hydrometer test. A parallel test is also carried out, in which no chemical dispersant is added and the solution is not mechanically excited. The quantity of particles finer than $0.005 \mathrm{~mm}$ in the parallel test is explicit as a percentage of this fraction determined in the standard test, which is defined as the dispersion ratio or dispersivity of the soil [6]. Dispersion ratios greater than $50 \%$ are observed extremely dispersive, between $30 \%$ and $50 \%$ are moderately dispersive, between $15 \%$ and $30 \%$ are a little dispersive and less than $15 \%$ are non-dispersive [7]. Similar systems with various limits were used by [1]-[19], and the dispersion test was first described by Volk (1937) [19] as a means of determining the potential dispersive of soils. The test has since been utilized extensively in this concern with minor modifications. Volk's test contrasts the weight of soil grains, $0.005 \mathrm{~mm}$ or smaller that slaked free when air-dried lumps of soil were soaked in silent distilled water with that of the complete soil. This was shown as the percentage dispersion. Measurements of the clay in the soil-water suspension were made by the pipette method [19].

The pipette method itself was announced by Middleton in 1930 as a means of determining the erosion potential of a soil. The difference in the methods was that the samples collected in the pipette depend on particles of a maximum diameter of $0.05 \mathrm{~mm}$ [16]. Volk's method was, however, chosen because studies in the southwest of the United States point out that the dispersion of the clay fraction $(<0.005 \mathrm{~mm}$ diameter) was more significant in assessing the piping potential of soils [20]. The SCS involvement in earth dam construction in the United States reproduces in the 1940's and early 1950's. The dispersion test was used as a routine procedure for all samples submitted to SCS Laboratories. It was during this time that the test procedure was appropriate to utilize a hydrometer to instate a pipette [20].

\section{Materials Methods}

This study was performed in Sulaimani Governorate to determine the effect of ten land use and clay content on dispersion ratio. The soil samples from $0-30 \mathrm{~cm}$ depth were collected from different locations. All soil samples were air dried, sieved through a $2 \mathrm{~mm}$ physical properties were measured such as particle size distribution by the pipette method, bulk density by Clod method. A single point using water under isothermal condition was measured the (SSA) according to [17]. Chemical properties were measured like soil organic matter which determined by the Walkley-Black method (1934) [21] and calcium carbonate by titration method.

\section{Micro Aggregate Stability}

This was calculated from the amount of silt and clay in calgon-dispersed as well as water-dispersed samples using Bouyoucos hydrometer method of particle size described by [22]

The clay-dispersion indices were calculated as follows:

$$
\text { Dispersion ratio }(\mathrm{DR})=\frac{(\text { silt }+ \text { clay }) \% \text { for the soil dispersed in water }}{(\text { Silt }+ \text { clay }) \% \text { for the soil dispersed by using Mechanical and chemical dispersion }}
$$

Clay dispersion index: 


$$
\text { (CDI }) \frac{\% \text { Clay } \mathrm{H}_{2} \mathrm{O}}{\% \text { Clay }(\text { Calgon })} \times 100
$$

\section{Statistical Analysis}

Correlation and regression were used to analyze the relationship between land use and some soil parameters of the samples (Figure 1). Analysis of variance (ANOVA) for complete randomized design (CRD) was used to compare the influence of the land usage types on the measured soil properties. DUNCAN at $\mathrm{P}<0.5$ level was used to separate the mean where applicable.

\section{Results and Discussions}

The soil texture of the study area was significantly affected by land use. Data obtained in Table 1 showed the variation in sand, silt and clay fraction of the soil. The result shows that the textural class across all the land use types of the study area is different soil texture, indicating the different of parent material. The result is in agreement with [23]. However, over a very long period of time, paedogenesis processes such as erosion, deposition, eluviations, and weathering can change the soil texture. Data in Table 1 relationship between clay dispersion ratio and dispersion ratio the highest value of clay dispersion ratio is $83.33 \%$ in Zrguezi Gawra (cultivated with Cucumber) and the lowest value is $11.29 \%$ in Azmar (Forest soil) and dispersion ratio the highest value is $40 \%$ in Zrguezi Gawra (cultivated with Cucumber) and the lowest value is 13\% in Dukan (Bare soil).

Data in Table 2 bulk density was highly impact by land use, the highest value in Zrguezi Gawra (cultivated with cucumber) is $1.73 \mathrm{~g} / \mathrm{cm}^{3}$ and lowest value in Azmar (forest soil) is $1.29 \mathrm{gm} / \mathrm{cm}^{3}$. This was in agreement with works of [15] [18], who supposed that the significant difference is caused differences in the land management and land use history, and other reason may be due to the high content of OM which reduced bulk density. Loss of organic matter by transformation of the natural forest in to pasture and cultivated land caused a higher bulk density in cultivated soils. The greatest soil bulk density was observed in cultivated and followed by pasture and forest land, similar result were reported by [12].

Organic matter was highly affected by land use. The highest value in Azmar is 3.2\% in this case deepened on land use (Forest soil) and the lowest value in Dukan, depended on land use (bare soil), may be as a result of

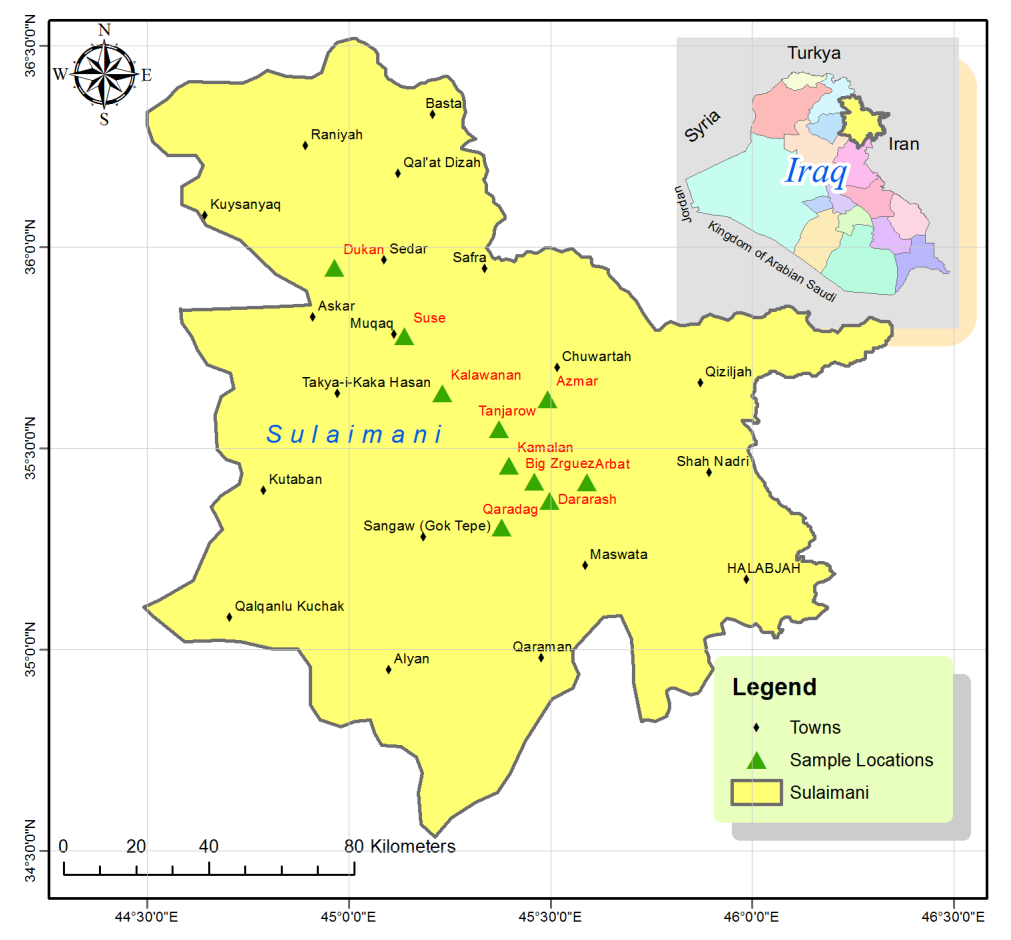

Figure 1. Site of soil samples. 
Table 1. Effect of Land Use on particles size distribution of Soil, Clay dispersion index and dispersion ratio in Sulaimani Governorate.

\begin{tabular}{ccccccc}
\hline Land Use Type & Sand (\%) & Silt (\%) & Clay (\%) & Soil texture & $\begin{array}{c}\text { Clay dispersion } \\
\text { index (CDI) \% }\end{array}$ & $\begin{array}{c}\text { Dispersion ratio } \\
\text { (\%) }\end{array}$ \\
\hline Arbat (Cultivated with Celery) & 7 & 41 & 52 & Silty Clay & 23.07 & 24 \\
Azmar (Forest Soil) & 7 & 31 & 62 & Clay & 11.29 & 16 \\
Zrguezi Gawra (Cultivated with Cucumber)) & 55 & 27 & 18 & Sandy Loam & 83.33 & 40 \\
Dararash (Cultivated with Melon) & 47 & 24 & 29 & Sandy Clay Loam & 34.48 & 38 \\
Dukan (Bare Soil) & 11 & 49 & 40 & Silty Clay & 12.5 & 13 \\
Kalawanan Cultivated with Water Melon) & 31 & 38 & 31 & Clay Loam & 25.8 & 25 \\
Kamalan (Cultivated with Wheat) & 55 & 10 & 35 & Sandy clay & 14.28 & 18 \\
Qaradag (Cultivated with Barley) & 17 & 50 & 33 & Silty Clay Loam & 33.33 & 28 \\
Suse Cultivated with Tomato ) & 25 & 49 & 26 & Loam & 34.61 & 35 \\
Tanjarow (Cultivated with Eggplant) & 20 & 54 & 26 & Silt Loam & 46.15 & 30
\end{tabular}

Table 2. Effect of Land Use on bulk density, organic matter, calcium carbonate and specific surface area in Sulaimani governorate.

\begin{tabular}{|c|c|c|c|c|}
\hline Land Use Type & $\begin{array}{l}\text { bulk density } \\
\left(\mathrm{gm} / \mathrm{cm}^{3}\right)\end{array}$ & $\begin{array}{c}\text { Organic matter } \\
\text { (\%) }\end{array}$ & $\begin{array}{c}\text { Calcium carbonate } \\
\text { (\%) }\end{array}$ & $\begin{array}{l}\text { Specific Surface Area } \\
\left(\mathrm{m}^{2} / \mathrm{gm}\right)\end{array}$ \\
\hline Arbat (Cultivated with Celery) & 1.33 & 2.3 & 24.39 & 130.80 \\
\hline Azmar (Forest Soil) & 1.29 & 3.2 & 13.91 & 150.33 \\
\hline Zrguezi Gawra (Cultivated with Cucumber)) & 1.73 & 1.2 & 21.35 & 75.26 \\
\hline Dararash (Cultivated with Melon) & 1.45 & 1.8 & 27.35 & 98.32 \\
\hline Dukan (Bare Soil) & 1.35 & 1.1 & 18.35 & 73.55 \\
\hline Kalawanan Cultivated with Water Melon) & 1.63 & 1.5 & 32.35 & 100.18 \\
\hline Kamalan (Cultivated with Wheat) & 1.38 & 2.5 & 29.35 & 142.23 \\
\hline Qaradag (Cultivated with Barley) & 1.53 & 1.9 & 20.35 & 122.07 \\
\hline Suse Cultivated with Tomato ) & 1.67 & 1.3 & 27.35 & 95.75 \\
\hline Tanjarow (Cultivated with Eggplant) & 1.55 & 1.7 & 35.39 & 97.22 \\
\hline
\end{tabular}

plant litter sufficient returned to the soil in these environments.

Calcium carbonate was highly affected by land use, the highest value in Tanjarow (35.39\%) and the lowest value in Azmar (13.91), This was in agreement with works of [13].

Soil specific surface area was highly affected by land use, the highest value in Azmar (forest soil) (150.33) and the lowest value in Dukan (Bare soil) (73.55).

Table 3 shows the relationship between dispersion ratio and selected soil physical and chemical properties correlation model determination. There is a positive correlation between dispersion ratios with clay, the result is in disagreement with [9] [10] [14], with bulk density and organic matter was positively correlated, the result is in agreement with [11]. A negative correlation also estimates between dispersion ratio with sand, silt, specific surface area and calcium carbonate.

In this table showed the clay, soil bulk density and organic matter have a significantly on the dispersion ratio value is $(0.0170,0.0118$ and 0.0130$)$ respectively.

Figures 2-9 showed the relationship between dispersion ratio and selected soil physical and chemical properties parameter, regression model and coefficient of determinations. There is a positive correlation between dispersion ratio with sand, bulk density, $\mathrm{CaCO}^{3}$ and $\mathrm{CDI}$ coefficient of determination value is $(0.247,0.568,0.114$ 
Table 3. Correlation between dispersion ratio with soil physical and chemical properties.

\begin{tabular}{cccc}
\hline Variable & By Variable & Correlation Coefficient & Significant Probability \\
\hline Dispersion ratio & Sand & 0.4979 & 0.1430 \\
Dispersion ratio & Silt & 0.0126 & 0.9724 \\
Dispersion ratio & Clay & -0.7281 & $0.0170^{*}$ \\
Dispersion ratio & Soil bulk density & 0.7536 & $0.0118^{*}$ \\
Dispersion ratio & Soil Specific Surface Area & -0.4466 & 0.1957 \\
Dispersion ratio & Organic Matter & -0.7472 & $0.0130^{*}$ \\
Dispersion ratio & Calcium Carbonate & 0.3381 & 0.3393
\end{tabular}

*Significant at $\mathrm{p} \leq 0.05$.

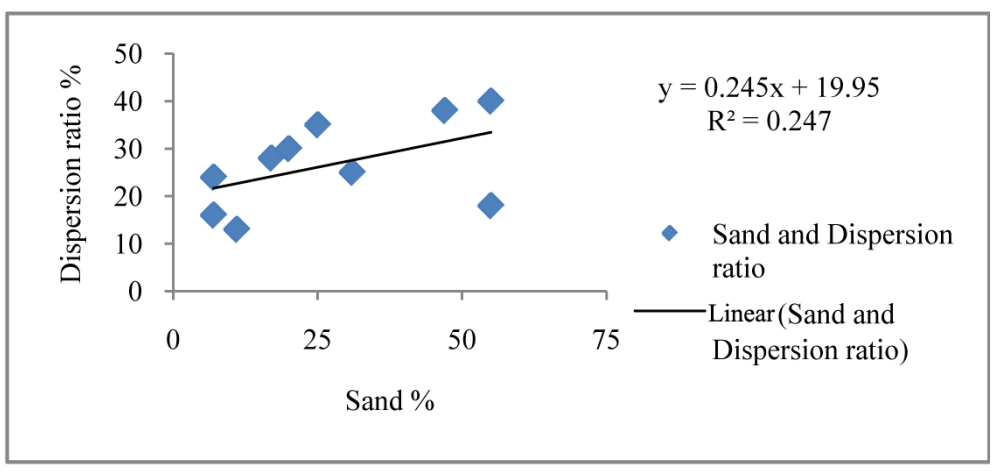

Figure 2. Effect of sand particle on dispersion ratio.

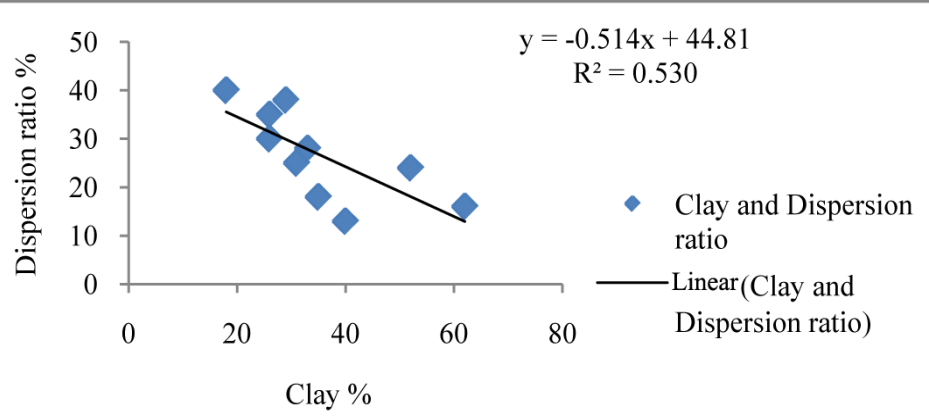

Figure 3. Effect of clay particle on dispersion ratio.

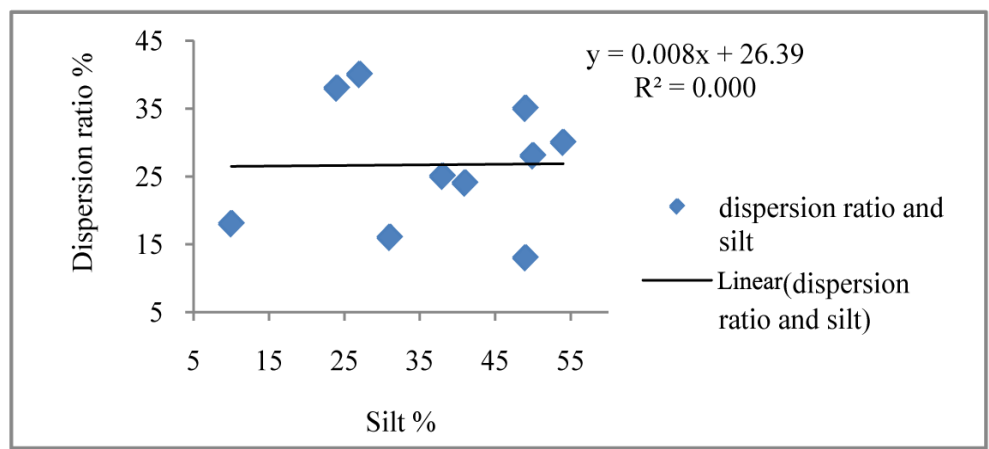

Figure 4. Effect of silt particle on dispersion ratio. 


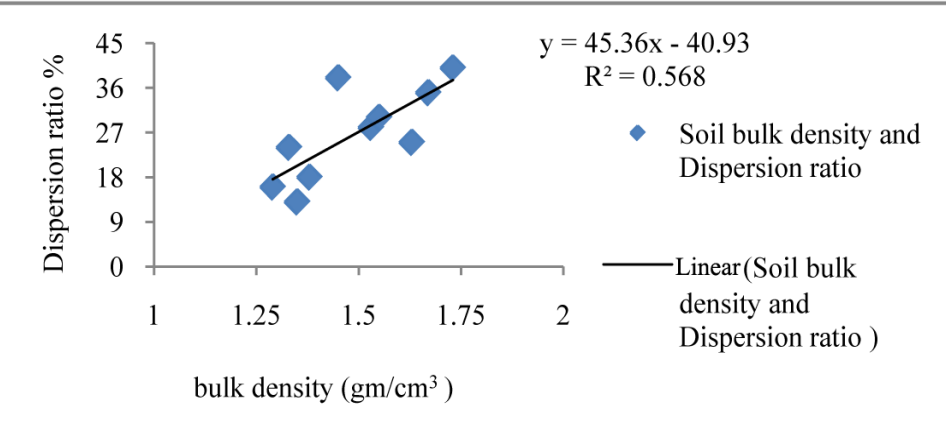

Figure 5. Effect of bulk density on dispersion ratio.

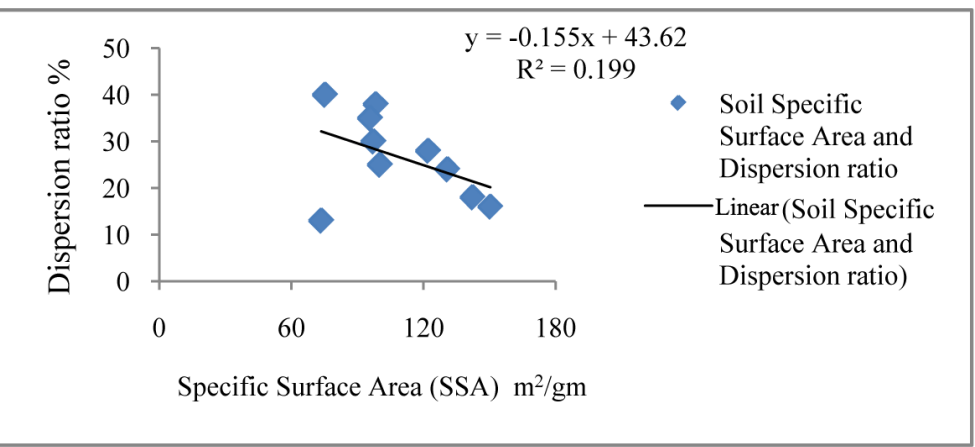

Figure 6. Effect of specific surface area on dispersion ratio.

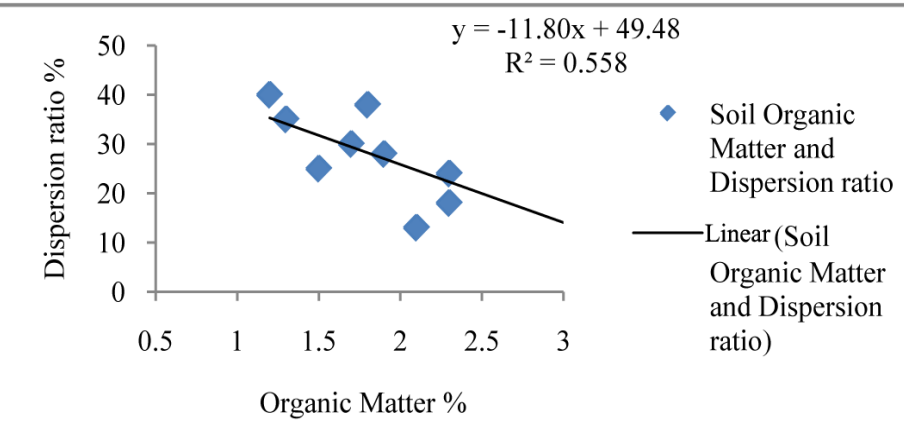

Figure 7. Effect of soil organic matter on dispersion ratio.

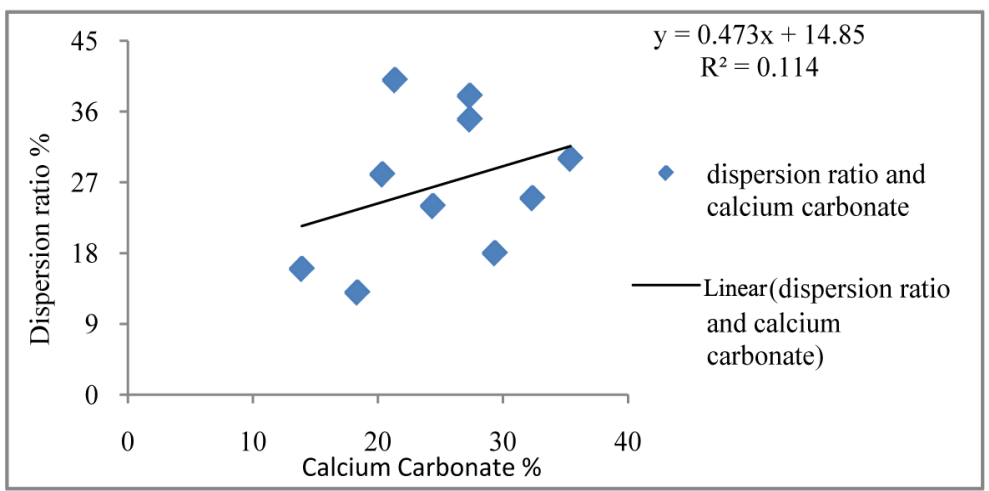

Figure 8. Effect of calcium carbonate on dispersion ratio. 


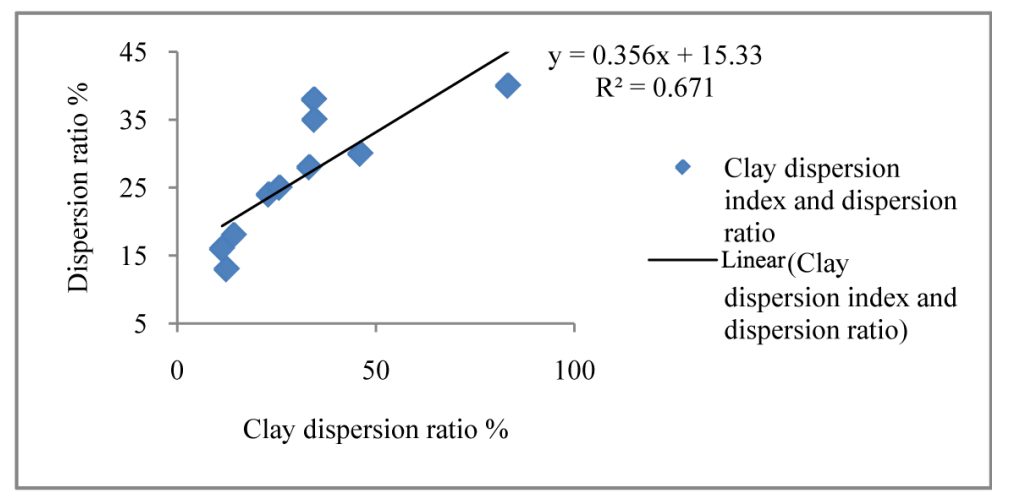

Figure 9. Effect of clay dispersion ratio on dispersion ratio.

and 0.671) respectively, and dispersion ratio negatively regression with clay, SSA and organic matter coefficient of determination value is $(0.530,0.199$ and 0.558$)$.

\section{Conclusion}

Variations in soil quality indicators with regard to land use were investigated in Sulaimani city, Kurdistan Region, Iraq. The most limiting soil properties impact quality and have significant effects on land use in the study area like soil organic matter, soil bulk density, soil texture and calcium carbonate. Among soil physical quality indicators, specific surface area and bulk density changed significantly with Land use and also among soil chemical quality indicators, soil organic matter and calcium carbonate varied significantly with land use.

\section{References}

[1] Paige-Green, P. (2008) Dispersive and Erodible Soils—Fundamental Differences. SAIEG/SAICE Problem Soils Conference, Midrand, November 2008, 59-67.

[2] Maharaj, A and Paige-Green, P. (2010) The Impact of Inconsistencies in the Interpretation of Soil Test Results on the Repeatable Identification of Dispersive Soils. Proceedings IAEG2010, Auckland, September 2010, 389-392.

[3] Maharaj, A. (2010) Preliminary Observations of Shortcomings Identified in Standard Tests for Dispersive Soils. Proceedings IAEG2010, Auckland, September 2010.

[4] Maharaj, A. (2011) the Use of the Crumb Test as a Preliminary Indicator of Dispersive Soils. Proceedings of the 15th African Regional Conference on Soil Mechanics and Geotechnical Engineering, Maputo.

[5] Maharaj, A. (2012) Problems Associated with the Chemical Analysis If Dispersive Soils. Proceedings of the 2nd European Conference on Unsaturated Soils (E-UNSAT 2012), Naples, 1-3 June 2012, 433-437.

[6] Walker, D.J.H. (1997) Dispersive Soils in KwaZulu-Natal. Unpublished M.Sc. Thesis, University of Natal, Durban.

[7] Elges, H.F.W.K. (1985) Problem Soils in South Africa-State of the Art. The Civil Engineer in South Africa, 27, 347353.

[8] Gerber, F.A. and Harmse, H.J. von M. (1987) Proposed procedure for identification of dispersive soils by chemical testing. The Civil Engineer in South Africa, 29, 397-399.

[9] Gu, B. and Doner, H.E. (1993) Dispersion and Aggregation of Soils as Influence by Organic and Inorganic Polymers. Soil Science Society of America Journal, 57, 709-716. http://dx.doi.org/10.2136/sssaj1993.03615995005700030014x

[10] Heil, D. and Sposito, G. (1993) Organic Matter Role in Illitic Soil Colloids Flocculation: I. Counter Ions and pH. Soil Science Society of America Journal, 57, 1241-1246. http://dx.doi.org/10.2136/sssaj1993.03615995005700050014x

[11] Igwe, C.A. (2001) Clay Dispersion of Selected Aeolian Soils of Northern Nigeria in Relation to Sodicity and Organic Carbon. Arid Land Research and Management, 15, 147-155. http://dx.doi.org/10.1080/15324980151062788

[12] Islam, K.R. and Weil, R.R. (2000) Land Use Effects on Soil Quality in a Tropical Forest Ecosystem of Bangladesh. Agriculture, Ecosystem \& Environment, 79, 9-16. http://dx.doi.org/10.1016/S0167-8809(99)00145-0

[13] Lahore Pour, Sh. (2004) The Effect of Grazing Intensity on the Physical and Chemical Properties of Soil in Charandsummer Pastures in Kurdistan. M.Sc. Thesis, Range Management, Tarbiat Modares University, Tehran, 68.

[14] Lebron, I. and Suarez, D.L. (1992) Variation in Soil Stability within and among Soil Types. Soil Science Society of America Journal, 56, 1412-1421. http://dx.doi.org/10.2136/sssaj1992.03615995005600050014x 
[15] Lemenih, M., Karltun, E. and Olsson, M. (2005) Assessing Soil Chemical and Physical Property Responses to Deforestation and Subsequent Cultivation in Small Holders Farming System in Ethiopia. Agriculture, Ecosystems \& Environment, 105, 373-386. http://dx.doi.org/10.1016/j.agee.2004.01.046

[16] Middleton, H.E. (1930) The Properties of Soils Which Influence Erosion. US Department of Agriculture Technical Bulletin, 178, 1-16. http://dx.doi.org/10.2136/sssaj1930.036159950b1120010021x

[17] Puri, B.R. and Murarri, K. (1963) Studiers in Surface Area Measurement of Soil. Surface Area from a Single Point on the Water Isotherm. Soil Science Journal, 96, 341-343.

[18] Sintayehu, M. (2006) Land Use Dynamics and its Impact on Selected Physicochemical Properties of Soils in YabelloWoreda of Borana Lowlands, Southern Ethiopia. M.S. Thesis, Haromaya University, Haromaya.

[19] Volk, G.M. (1937) Method of Determination of Degree of Dispersion of the Clay Fraction of Soils. Proceedings of Soil Science Society of America, 2, 561-567. http://dx.doi.org/10.2136/sssaj1938.036159950002000C0088x

[20] Decker, R.S. and Dunnigan, L.P. (1977) Development and Use of the Soil Conservation Service Dispersion Test. In: Sherard, J.L. and Decker, R.S., Eds., Proceedings of Symposium on Dispersive Clays, Related Piping and Erosion in Geotechnical Projects, ASTM Special Publication, Vol. 623, 94-109. http://dx.doi.org/10.1520/stp26982s

[21] Walkley, A. and Black, C.A. (1934) An Examination of the Degtjareff Method of Determining Soil Organic Matter and a Proposed Modification of the Chronic Acid Titration Method. Soil Science, 37-38.

[22] Gee, G.N. and Bauder, J.W. (1986) Particle Size Distribution. In: Klute, A., Ed., Methods of Soil Analysis Part 1. Physical and Mineralogical Methods, 2nd Edition, Agronomy Society of America/Soil Science Society of America, Madison, Wisconsin, 383-411.

[23] Abera, Y. and Belachew, T. (2011) Effects of Landuse on Soil Organic Carbon and Nitrogen in Soils of Bale, Southeastern Ethiopia. Tropical and Subtropical Agroecosystems, 14, 229-235. 